\title{
Research Regarding the Manufacturing through AM Technologies of an Implant for Cervical Disc Replacement
}

\author{
Cristina Stefana Miron-Borzan ${ }^{1, *}$, Emilia Sabau ${ }^{1}$, Mircea Mera $^{1}$ and Petru Berce ${ }^{1}$ \\ ${ }^{1}$ Technical University of Cluj-Napoca, Manufacturing Engineering Department, 103-105 Muncii Bvd. \\ Cluj-Napoca, Romania
}

\begin{abstract}
Worldwide, accidents are one of the main causes of illness in developed and undeveloped socio-economic countries. Additive Manufacturing (AM) technologies bring extremely useful and advantageous applications for the new neurosurgical procedures. Because the surgical insertion of devices for cervical disc replacement is very difficult, the development of new devices that can minimize these disadvantages, are needed. The aim of this paper was to improve the characteristics of an implant for cervical intervertebral disc replacement, a model based on an existing implant. A cervical cage designed for stabilization and arthrodesis between the cervical vertebrae was analyzed. A new design of a cage that have some improvements, useful for patient safety, as well as for facilitating the surgery was developed. The new proposed design was verified through Fine Element Analysis.
\end{abstract}

\section{Introduction}

The human body is a complex system composed of structured devices coordinated by the central nervous system. Each part of the human body must function at optimal parameters. The components of the human body are part of some complex subsystems and their optimal function makes the proper functioning of the other components. In the case of an accident or disease the intervention of a surgeon is required and a prosthesis can resume the activity of an organ, or part of the body [1].

The cervical cage is an intersomatic cage whose main function is to maintain the disc height and the radicular decompression by intersomatic distraction. Its design is favoring osteogenesis. It have a convex shape on its supper face and has openings on the upper and bottom faces. It comes in several heights so it is able to adapt to the variable morphology of the intervertebral spaces [2]. The criteria required to an ideal cage for cervical interbody fusion are the following: providing immediate stability, maintaining spinal alignment and foraminal height, achieving higher or at least equal fusion success rate, and obviating complications by using autograft [2].

Cervical total disc replacement has been accepted as a viable option for surgical management of cervical spondylosis or degenerative disc disease [3].

${ }^{*}$ Corresponding author: borzan_cristina@ymail.com 
Performing a cervical discectomy by an interbody fusion is one of the surgical procedures for the treatment of cervical degenerative disc disease. Although high fusion rates have been reported with autogenous bone grafts, the immediate and long-term morbidity associated with an iliac crestharvestis well recognized [4].

The requirements for an appropriate cage height and shape must be estimated prior to surgery. Must been compared the X-ray template for Cage with the adjacent intervertebral discs on a lateral radiograph. With the segment fully distracted, the implant must fit tightly and accurately between the end plates. The final choice of height and shape will be made with the help of a trial implant during surgery. To achieve maximum segment stability, it is essential to implant the largest possible cage [5]. The sizes of an existing Cage are presented in Figure 1.
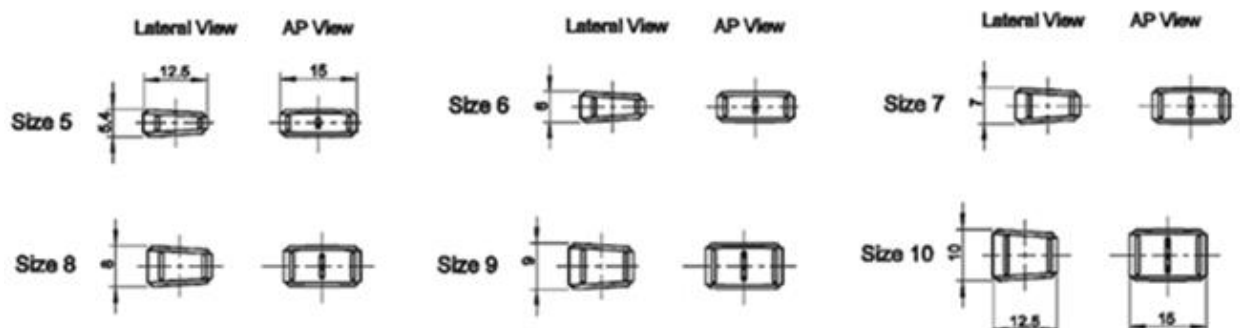

Fig. 1. The sizes for a Cage [5].

Currently, worldwide there are many companies that produce medical devices widely, used in new techniques of spinal neurosurgery.

Polyetheretherketone (PEEK) and Titanium (Ti) are two biocompatible materials that are used in manufacture of Cages through AM technologies. In the scientific literature there are many studies focused on PEEK and Ti cages. Initially, the threaded cylindrical titanium cages that became popular in the late 1990's helped the success rate of the procedure by providing more firm fixation of the disc space. Petter Ullrich [6] presents anterior interbody cages from titanium cylinders that are placed in the disc space. The cages are porous and allow the bone graft to grow from the vertebral body through the cage and into the next vertebral body. The cages offer excellent fixation, so most patients do not need additional instrumentation (e.g. pedicle screws) or post-operative back braces for support. Other authors [7-9] showed that Titanium or carbon fiber cages were widely used for cervical interbody fusion, but in some cases subsidence, migration, or structure failure had occurred.

PEEK cages have been widely used during the past decade in patients with degenerative disorders of the cervical spine [10]. The PEEK cages are biocompatible, radiolucent, and have modulus of elasticity similar to the bone [7].

Studies focused on clinical cases also showed that the actual used PEEK cages have a better behavior than pure Ti cages after implantation. A direct comparison of cervical $\mathrm{Ti}$ and PEEK cages in a clinical setting is very rarely found in the literature $[11,12,13,14]$, and even less studies consequently compare the radiological results $[16,18]$. The latter studies showed the PEEK-implants being superior in maintaining cervical interspace height and achieving radiographic fusion $[11,13]$, even suggesting to cease the application of $\mathrm{Ti}$ cages in cervical spine surgery $[11,15]$.

The Cages can be manufactured through AM Technologies. If the Ti powder is used, the recommended method is Selective Laser Melting process (SLM) and in the case of PEEK, the Selective Laser Sintering process (SLS). Selective laser sintering, 3-dimensional 
printing is currently used for industrial manufacturing of plastic, metallic and ceramic objects [16]. The SLS process is based on the realization of a CAD product by adding successive layers. The laser (carbon dioxide type) covers the entire surface of the section (point by point), sintering fine layer of material deposited on the working platform [17].

Selective Laser Melting (SLM) is an additive metals manufacturing technology with a presence in medical orthopedics, dental, aerospace, high technology engineering and electronics sectors. The process uses a high powered laser to fuse fine metal powders together, layer by layer direct from CAD data, to create functional metal parts [17].

The aim of this paper was to improve the characteristics of an implant for cervical intervertebral disc replacement in order to prevent its migration, to facilitate the surgery and to evaluate his behavior during extension of the head through Fine Element Analysis.

\section{Materials and Method}

Based on the analysis of the existing Cage implant was developed a new Cage, that have some improvements, useful for the patient's safety and to facilitate surgery. Initially a standard-type Cage, which kept the dimensions of an existing Cage was made (Figure 2). The design was done in Solid Works software with the maximum dimensions required for a Cage- size 10.

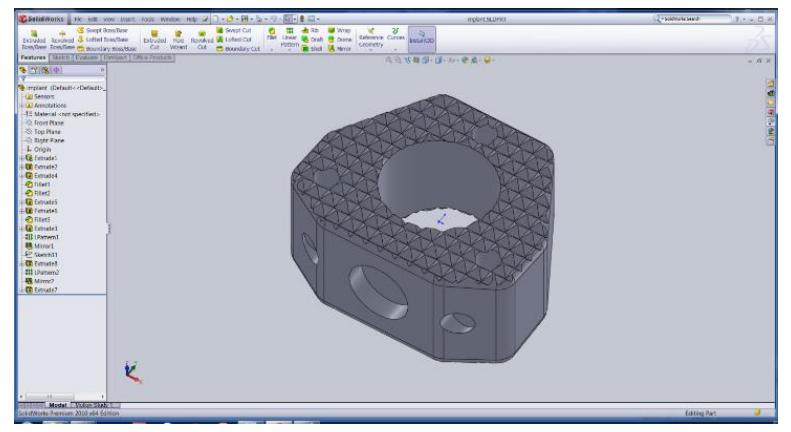

Fig. 2. The proposed model for analyze.

To prevent the migration after implantation, the new proposed implant has two "ears" for fixing the Cage on neighboring vertebrae. The implant can be fixed with the help of two self-tapping screws, from Titanium Alloys, biocompatible. The new model presents holes in correlation with the dimensions of the screws' head. In order to verify the new model, the implant was manufactured from pure Ti using SLM process $(120 \mathrm{~W}$ laser power and $500 \mathrm{~mm} / \mathrm{s}$ scan speed).

In the scientific literature, there are studies made in the field of stresses from the cervical spine. One of the authors [18], showed that the weight on the spine dramatically increases when flexing the head forward at varying degrees. An adult head weighs 10 to 12 pounds in the neutral position. As the head tilts forward the forces seen by the neck surges to 27 pounds at 15 degrees, 40 pounds at 30 degrees, 49 pounds at 45 degrees and 60 pounds at 60 degrees. At 90 degrees the model prediction was not reliable.

For analyzing the forces in the cervical spine, taking into account flexing the head, the pounds were transformed into Kilograms $[\mathrm{Kg}]$ and after in Newtons [N] (table 1).

Table 1. The forces in the cervical spine taking into account flexing the head forward

\begin{tabular}{|l|l|l|l|l|l|}
\hline Position & Neutral & 15 & 30 & 45 & 60 \\
\hline $\begin{array}{l}\text { Force applied to the } \\
\text { Cervical Column [N] }\end{array}$ & $45-54$ & 122 & 181 & 222 & 271 \\
\hline
\end{tabular}




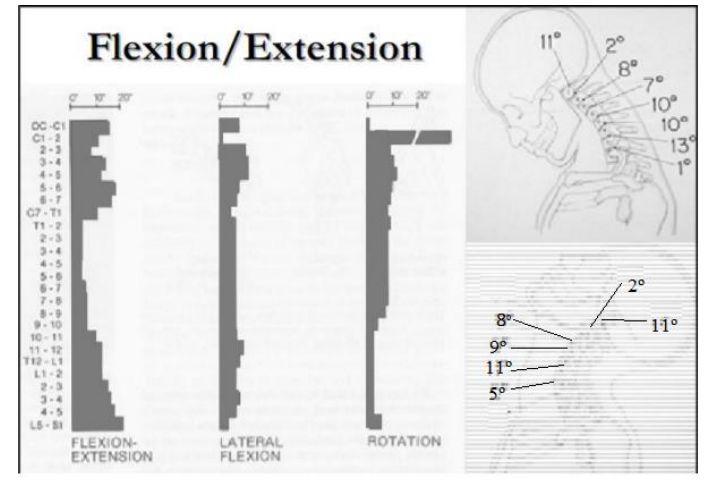

Fig. 3. The flexing positions and angles for the human neck [19].

We considered the theoretical case, when the flexing and extension forces are equal, figure 3. In order to analyze the forces and the stresses in the fixing area of the implant, a FEA analyze was made in the ANSYS Software. The analysis was done in the case of the maximum load $(271 \mathrm{~N})$, for pure Ti and PEEK, materials that can be used in the Cage manufacturing. The mechanical properties for PEEK parts manufactured through SLS are: Density $1310 \mathrm{~kg} / \mathrm{m}^{3}$, Tensile Modulus 4250MPa, Tensile Strength 90MPa, Strain at break $2,8 \%$ [20] and for pure Ti, manufactured at $120 \mathrm{~W}$, the mechanical properties are: Density $4510 \mathrm{~kg} / \mathrm{m}^{3}$, Tensile Strength 440MPa, Young Modulus 100GPa, Poisson's Ratio 0.35 [21].

\section{Results and Discussions}

Nowadays, numerical simulation represents a very effective method for simulating various processes including all common engineering materials [22]. The Finite Element Analysis (FEA) is a numerical solution of the problems that can be expressed in mathematical language in the form of partial derivative equation systems. The meshing concept is found at FEA base. In very intuitive terms, the meshing operation is a division of the spatial domain occupied by the analyzed body into regions of limited sizes known as finite elements. At present, there are a large number of commercial programs for finite element analysis. Among the best known are ANSYS, ASTRAN, ALGOR, ABAQUS etc.

For this research the ANSYS 16.0 Software was used. The first proposed objective was to analyze and to determine the stress state and the deformation of the implant. The following kinematic restrictions were imposed on the model, namely: applying forces on the right and left sides of the implant (where will be the contact area with the screws), like in the Figure 4. The left side and the right side of the piece takes up a force of 135,5 $\mathrm{N}$ (traction). We considered that the value strength of $271 \mathrm{~N}$ is equal taken by the both sides. Finite elements were used in order to meshing the implant, the thickness of the elements were of $0.50 \mathrm{~mm}$ (the same size on the entire surface of the model), Figure 5.

Figure 6 shows the distribution of the von Mises equivalent stress in the implant model. It can be seen that the maximum value for the pure Ti material was 35,182 MPa (Figure 6, a) and the maximum value for the PEEK: 34,889 MPa (Figure 6, b).

The difference between these two materials is very small, about 0,293 MPa. We can conclude, that from the point of view of stress trials, this two used materials have a good behavior.

In the case of the total deformation for the pure $\mathrm{Ti}$ material the maximum value was $0,009 \mathrm{~mm}$ (Figure 7, a) and the maximum value for the PEEK was 0,233 $\mathrm{mm}$ (Figure 7, b). 


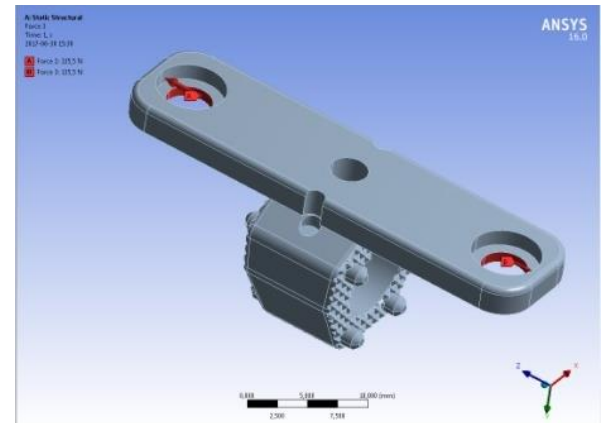

Fig. 4. Kinematic restrictions

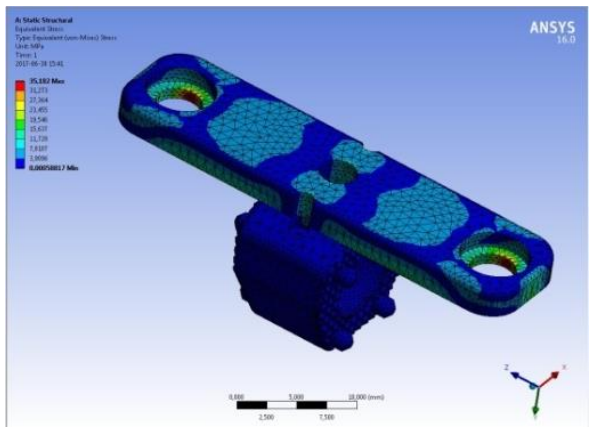

a. Pure Ti material

Fig. 6. Distribution of the von Mises stress

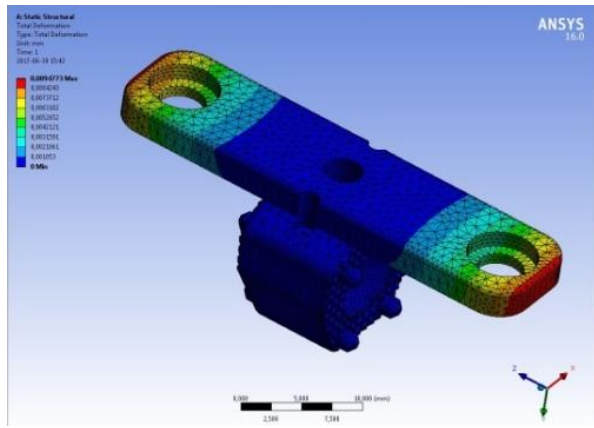

a. Pure Ti material

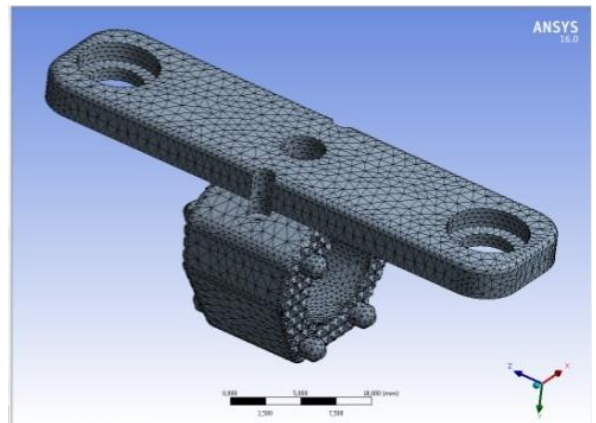

Fig. 5. Finite element network

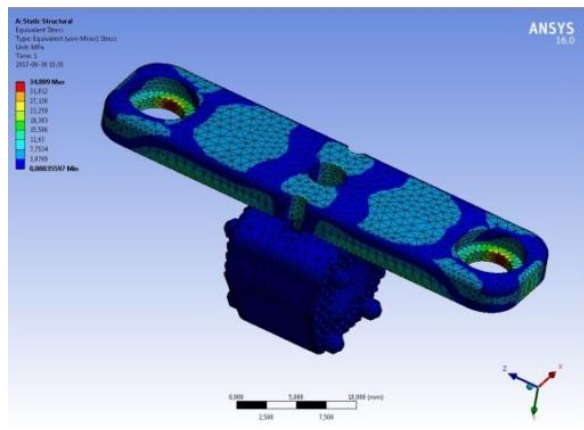

b. PEEK material

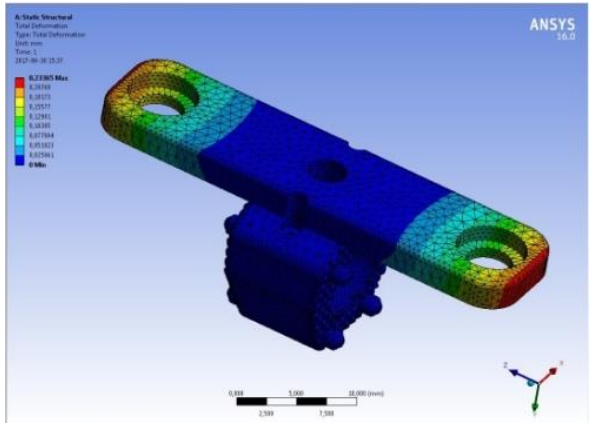

b. PEEK material

Fig. 7. Total deformation.

The difference between these two materials is about $0,224 \mathrm{~mm}$. In this case the deformation for the PEEK material is larger than in the case of pure Ti material. We can conclude that for this model, the pure $\mathrm{Ti}$ is more rigid than the PEEK material which has a higher elasticity. PEEK has a better behavior for this kind of application and for the anatomical structure taking into account his modulus of elasticity similar to the bone. For the proposed design of the cage even if pure Ti cages have a good resistance and behavior from the point of view of stresses, PEEK cages seems to be more close to the required anatomical structure in cervical area. The presented example demonstrates the possibility of implementing the proposed model in the structure of finite element analysis programs. If the material resistance is undersize or oversize, we will also optimize the shape. The 
decision of optimization will be taken by reporting to a safety factor of the von Mises stress $\mathrm{C}=1,50$.

\section{Conclusions}

A new implant for cervical disc replacement (cage) was developed. The new proposed model was manufactured through SLM process and has some improvements, helpful for the patient's safety and for facilitating the surgery. This paper analyzed implants from pure Ti and PEEK using the ANSYS 16.0 Software. The analysis proposed to determine the stress state during extension of the head and the deformation of the implant. We considered that the value strength of $271 \mathrm{~N}$ is equal took by the both sides of the implant. The left and the right side (ears) of the piece takes up a force of 135,5 $\mathrm{N}$ (traction). From the point of view of stress trials these two used materials have a good behavior. The pure Ti is more rigid than the PEEK material, but PEEK has a higher elasticity. For the proposed design of the cage even if pure $\mathrm{Ti}$ cages have a good resistance and behavior from the point of view of stresses, PEEK cages seems to be more close to the required anatomical structure in cervical area. Also, the presented example demonstrates the possibility of implementing the proposed model in the structure of finite element analysis programs.

This work was supported by a grant of the Romanian National Authority for Scientific Research and Innovation, CNCS/CCCDI-UEFISCDI, project number PN-III-P2-2.1-BG-2016-0216, within PNCDI III.

\section{References}

1. C. Borzan, Manufacture of Customized Implants from Biocompatible Materials (Master Thesis, UTCN, Cluj-Napoca, 2011)

2. Corbel Instructions, Établissement SpineNetwork, Surgiview, France

3. T.-H.Tu, J.C.Wu, L.-Y.Fay, C.-C.Ko, et all, J Neurosurg Spine, 16, 211 (2011)

4. M. Y. Chang, M. H. Chen, C. J. Chang, J. S. Huang, FJS, 46, 4 (2013)

5. Synthes, Cervios and CerviosChronOS, Technique Guide

6. P. F. Ullrich, Spine-Health, (2004)

7. J.C. Liao, C. C.Niu, W.-J. Chen, L.H. Chen, IntOrthop, 32, 5 (2008)

8. C.C. Niu, L.H. Chen, P.L. Lai, T.S. Fu, W.J. Chen, Chang Gung Med J.,28, 4 (2005)

9. I Haven, PJ Loon, RH Bartels, JL Susante ActaOrthop Belg., 71, 5 (2005)

10. F. Roel, M.R.Kersten, S.M.van Gaalen, et all, The Spine J., 15, 6, (2015)

11. Y.C. Chou, D.C. Chen, W.A. Hsieh, W.F. Chen, et all, J Clin Neurosci. 15, 11 (2008)

12. U. Meier, D. Kemmesies, Orthopade, 33, 11 (2004)

13. C. Niu, J.C. Liao, W.J. Chen, L.H. Chen, J Spinal Disord Tech., 23, 5 (2012)

14. G. Matge, Acta Neurochir, 144, 6 (2002)

15. M. Cabraja, S. Oezdemir, D. Koeppen, S. Kroppenstedt, BMC Musculoskelet Disord, 13, $172(2012)$

16. F. Fina, A. Goyanes, S.Gaisford. A. W.Basit, Int. J. of Pharmaceutics (2017)

17. P.Berce, N. Bâlc, ş.a. Fabricarea Rapidă a Prototipurilor (EDP Tehnică, Buc., 2000)

18. K. K. Hansraj, Neuro and Spine Surgery, Surgical Techn. Int. XXV (2014)

19. *** http://web.iitd.ac.in/ achawla/public_html/736/12-biomech-I-head-neck-v2.pdf

20. EOS GmbH - Electro Optical Systems, EOS PEEK HP3, Material Data Sheet

21. A. Ispas, C. Cosma, et all, J Optoelectron Adv M, 18, 9-10 (2016)

22. P. Bella, P.Buček, M.Ridzoň, M. Mojžiš, L.Parilák, Key Engineering Materials, 716 708 (2016). 